\section{Correspondence on 'Immunogenicity and safety of anti-SARS-Cov-2 mRNA vaccines in patients with chronic inflammatory conditions and immunosuppressive therapy in a monocentric cohort'}

We read with great interest the article by Geisen et al. ${ }^{1}$ The authors reported a considerable immunogenicity of mRNA vaccines against SARS-CoV-2 in patients with chronic inflammatory diseases receiving immunosuppression; noteworthy, none was on B-cell depleting agents.

Rituximab (RTX) is one of the mainstays of antineutrophil cytoplasmic antibodies (ANCA)-associated vasculitis (AAV) treatment, both for induction and maintenance therapy ${ }^{2}$; of note, recent data have shown that RTX therapy was associated with poorer COVID-19-related outcomes in patients with rheumatic diseases. ${ }^{3}$

In the absence of an effective treatment, vaccination would be a promising tool to prevent severe COVID-19 in immunocompromised patients.

Only four cases addressing the issue of antibody production after SARS-CoV-2 infection in patients with AAV treated with RTX are available in literature, ${ }^{4-6}$ while no data about antibody production after vaccination have been published yet.

We describe here the case of two AAV patients who did not produce neutralising antibodies after mRNA vaccination against SARS-CoV-2 (cases 1 and 2); we also report the case of a patient who experienced COVID-19 while B-cell depleted without seroconversion (case 3).

Case 1: a 31-year-old woman presenting with nasal crusting and saddle nose deformity, bilateral effusive otitis media, isolated microhaematuria and anti-myeloperoxidase (MPO) positive ANCA, was diagnosed with granulomatosis with polyangiitis (GPA) in February 2018. Induction therapy consisted of glucocorticoids and 4 weekly infusions of RTX $(375 \mathrm{mg} /$ $\mathrm{m}^{2}$ ), obtaining complete remission. Subsequently, maintenance therapy was started, with four scheduled infusions of RTX (500 mg each) every 6 months. Last infusion was administered on the 26 June 2020. In January 2021, while on maintenance therapy with prednisone 5 and $2.5 \mathrm{mg}$ on alternate days, she received mRNA vaccine against SARS-CoV-2. At the time of vaccination, peripheral $\mathrm{B}$ cell count was 0 cells $/ \mathrm{mm}^{3}$, immunoglobulin levels were normal. No anti-SARS-CoV-2 spike protein antibodies were detectable at the test performed 60 days later (March 2021).

Case 2: a 60-year-old woman was diagnosed with MPO-ANCA positive GPA in October 2014. She presented with constitutional symptoms (fever, weight loss, weakness), bilateral dacryoadenitis and episcleritis, microhaematuria and low-grade proteinuria. She received glucocorticoids and two infusions of RTX (1 $\mathrm{g}$ each) 2 weeks apart for remission induction. Maintenance therapy with methotrexate was then started. From November 2018, she was retreated with RTX (four scheduled infusions of $500 \mathrm{mg}$ every 6 months) due to B-cell repopulation and ANCA positivity; methotrexate was withdrawn. Last RTX infusion was administered on 24 June 2020. In January 2021, she received mRNA vaccine against SARS-CoV-2. At that time, B-cell count was 0 cells $/ \mathrm{mm}^{3}$ and immunoglobulin levels normal. Maintenance therapy consisted of prednisone $5 \mathrm{mg} /$ day. Sixty days later (March 2021), no anti-SARS-CoV-2 spike protein antibodies were detectable.

Case 3: a 43-year-old woman was diagnosed with biopsy proven ANCA-negative localised GPA in September 2019. She had nasal crusting and subglottic stenosis. She received glucocorticoids and four infusions of RTX $\left(375 \mathrm{mg} / \mathrm{m}^{2}\right.$ each) for remission induction. Due to COVID-19 pandemic, a maintenance RTX infusion $(500 \mathrm{mg}$ ) was delayed to the 26 June 2020. In September 2020, peripheral B-cell count was 0 cells $/ \mathrm{mm}^{3}$ and immunoglobulin levels normal. From the 31 October 2020, she developed fever, cough, headache and weakness. On the 4 November 2020, a nasopharyngeal swab for SARS-CoV-2 tested positive. She was treated with glucocorticoids, enoxaparin and azithromycin with complete recovery and no need for hospitalisation. In March 2021, she underwent a serological test for antiSARS-CoV-2 spike protein antibodies and none was detected.

In patients treated with RTX, a blunted response to several vaccinations, including those against seasonal influenza, Pneumococcus and tetanus, ${ }^{78}$ has already been reported.

Of note, the two patients here described did not develop neutralising antibodies after mRNA vaccine against SARS-CoV-2, even though last infusion of RTX dated back to 9 months earlier.

Data on seroconversion after SARS-CoV-2 infection in AAV patients treated with RTX are scanty but available. To date, only four cases have been published: three patients were B-cell depleted and one B-cell reconstituted $\left(10\right.$ cells $\left./ \mathrm{mm}^{3}\right)$ at the time of the infection. Of note, the latter developed IgG towards SARS-CoV-2 while, among the former three, only one showed low titre of neutralising antibodies (table 1 ).

Guidelines for RTX treated patients recommend to perform vaccination at least 4 weeks prior or 6 months after infusion. ${ }^{9}$ However, in AAV patients, a more delayed B-cell repopulation has been described compared with other immunological diseases. ${ }^{10}$ Of note, up to more than 60 months of B-cell depletion after induction with RTX has been described in AAV patients, suggesting an intrinsic dysregulation of the B-cell compartment in this disease. ${ }^{11}$ Therefore, in addition to the timing since last RTX infusion, we believe that in this group of patients also B-cell count should be taken into account when planning vaccination.

Although results from single case reports cannot be generalised, our data raise concerns about the risk of an inadequate seroconversion after SARS-CoV-2 vaccine in AAV patients treated with RTX.

\begin{tabular}{llllllll}
\hline \multicolumn{2}{l}{ Table 1} & \multicolumn{7}{l}{$l$} & \\
\hline Reference & Age & Sex & Diagnosis & Time from last RTX (days) & B cell count (cells/mm ${ }^{3}$ ) & Hypogammaglobulinaemia & Anti-SARS-CoV-2 IgG \\
\hline 4 & 73 & F & GPA & 45 & 0 & Yes & Negative \\
4 & 74 & F & MPA & 100 & 0 & No & Low level (39 AU/mL, cut-off $>10)$ \\
5 & 62 & F & AAV & 149 & 0 & N/A & Negative \\
6 & 64 & F & MPA & 82 & 10 & No & Positive \\
Present manuscript & 43 & F & GPA & 127 & 0 & No & Negative \\
\hline
\end{tabular}


Chiara Salviani $\odot{ }^{1}$ Francesco Scolari, ${ }^{1,2}$ Federico Alberici ${ }^{1,2}$

${ }^{1}$ Nephrology Unit, ASST Spedali Civili di Brescia, Brescia, Italy

2Department of Medical and Surgical Specialties, University of Brescia, Brescia, Italy

Correspondence to Dr Chiara Salviani, Nephrology Unit, ASST Spedali Civili di Brescia, Piazzale Spedali Civili 1, 25125, Brescia, Lombardia, Italy; chiara.salviani@gmail.com

Contributors CS planned the study, collected the data, drafted the manuscript. FS planned the study, reviewed the manuscript. FA planned the study, recruited the patients, reviewed the manuscript.

Funding The authors have not declared a specific grant for this research from any funding agency in the public, commercial or not-for-profit sectors.

Competing interests None declared.

Patient and public involvement Patients and/or the public were not involved in the design, or conduct, or reporting, or dissemination plans of this research.

Patient consent for publication Not required.

Ethics approval Ethical approval for this study was obtained according to Italian regulations

Provenance and peer review Not commissioned; internally peer reviewed.

(C) Author(s) (or their employer(s)) 2021. No commercial re-use. See rights and permissions. Published by BMJ.

\section{A) Check for updates}

To cite Salviani C, Scolari F, Alberici F. Ann Rheum Dis 2021;80:e158.

Received 2 April 2021

Accepted 3 April 202

Published Online First 28 May 2021

Ann Rheum Dis 2021:80:e158. doi:10.1136/annrheumdis-2021-220496
ORCID iD

Chiara Salviani http://orcid.org/0000-0001-5556-0935

\section{REFERENCES}

1 Geisen UM, Berner DK, Tran F. Immunogenicity and safety of anti-SARS-Cov-2 mRNA vaccines in patients with chronic inflammatory conditions and immunosuppressive therapy in a monocentric cohort. Ann Rheum Dis 2021;80:1302-7.

2 Alberici F, Jayne DRW. Impact of rituximab trials on the treatment of ANCA-associated vasculitis. Nephrol Dial Transplant 2014:29:1151-9.

3 Strangfeld A, Schäfer M, Gianfrancesco MA, et al. Factors associated with COVID-19related death in people with rheumatic diseases: results from the COVID-19 global rheumatology alliance physician-reported registry. Ann Rheum Dis 2021;80:930-42.

4 Quartuccio L, Treppo E, Binutti M, et al. Timing of rituximab and immunoglobulin level influence the risk of death for COVID-19 in ANCA-associated vasculitis. Rheumatology 2021. doi:10.1093/rheumatology/keab175. [Epub ahead of print: 20 Feb 2021].

5 D'Silva KM, Serling-Boyd N, Hsu TY-T, et al. SARS-CoV-2 antibody response after COVID-19 in patients with rheumatic disease. Ann Rheum Dis 2021;80:817-9.

6 Suárez-Díaz S, Morán-Castaño C, Coto-Hernández R, et al. Mild COVID-19 in ANCAassociated vasculitis treated with rituximab. Ann Rheum Dis 2020;80:e99.

7 Houot R, Levy R, Cartron G, et al. Could anti-CD20 therapy jeopardise the efficacy of a SARS-CoV-2 vaccine? Eur J Cancer 2020;136:4-6.

8 Westra J, van Assen S, Wilting KR, et al. Rituximab impairs immunoglobulin (Ig)M and IgG (subclass) responses after influenza vaccination in rheumatoid arthritis patients. Clin Exp Immunol 2014;178:40-7.

9 Soy M, Keser G, Atagunduz P, et al. A practical approach for vaccinations including COVID-19 in autoimmune/autoinflammatory rheumatic diseases: a non-systematic review. Clin Rheumatol 2021:22:1-13.

10 Thiel J, Rizzi M, Engesser M, et al. B cell repopulation kinetics after rituximab treatment in ANCA-associated vasculitides compared to rheumatoid arthritis, and connective tissue diseases: a longitudinal observational study on 120 patients. Arthritis Res Ther 2017;19:101.

11 Salviani C, Jeannin G, Cancarini G, et al. Factors influencing B cell repopulation after remission induction with rituximab in newly diagnosed, treatment-naïve patients with anca-associated vasculitis. Rheumatology 2019;58:ii155. 